\title{
Mouthpart deformities in non-biting midge larvae from a cadmium contaminated stream in Northern Thailand
}

\author{
Pimchanoke Weeraprapan $^{\mathrm{a}}$, Somporn Chantara ${ }^{\mathrm{a}, \mathrm{b}}$, Munetsugu Kawashima ${ }^{\mathrm{a}}$, \\ Weerasak Roongruangwong ${ }^{\mathrm{a}, \mathrm{c}}$, Rungnapa Tagun ${ }^{\mathrm{d}}$, Chitchol Phalaraksh ${ }^{\mathrm{a}, \mathrm{c}, *}$ \\ a Environmental Science Program, Faculty of Science, Chiang Mai University, Huay Kaew Road, \\ Chiang Mai 50200 Thailand \\ b Department of Chemistry, Faculty of Science, Chiang Mai University, Huay Kaew Road, \\ Chiang Mai 50200 Thailand \\ c Department of Biology, Faculty of Science, Chiang Mai University, Huay Kaew Road, \\ Chiang Mai 50200 Thailand \\ d Department of Biology, Faculty of Science and Technology, Chiang Mai Rajabhat University, \\ Chang Phuak Road, Chiang Mai 50300 Thailand
}

*Corresponding author, e-mail: chitcholp@gmail.com

Received 20 Oct 2017

Accepted 31 Jan 2018

\begin{abstract}
Deformities in the mouthparts of non-biting midge larvae, particularly in the teeth of the mentum, were studied in cadmium polluted areas in Mae Tao Stream, Mae Sot District, Tak Province, Northern Thailand. Non-biting midge larvae were sampled together with water and sediment from 4 study sites: sites MT1 and MT2 were upstream to a zinc mine and unpolluted by cadmium; sites MT3 and MT4 were downstream and polluted with cadmium. From the water temperature, $\mathrm{pH}$, electrical conductivity, total dissolved solids, dissolved oxygen, nitrate-nitrogen, ammonia-nitrogen, and orthophosphate, the stream water quality was classified as moderately clean. The cadmium concentrations MT3 and MT4 exceeded the European maximum permissible level of $3.0 \mathrm{mg} / \mathrm{kg}$ for agricultural soil. A total of 3067 larvae and 21 taxa representing 3 subfamilies (Chironominae, Orthocladiinae, and Tanypodinae) from the four sampling sites were screened for mentum deformities. The results indicated that the deformity incidence of larvae was 5\% at MT3 and MT4 and $0.20 \%$ at MT1 and $0.75 \%$ at MT2. Hence the mouthpart deformities of non-biting midge larvae could be potentially used as a bio-indicator for cadmium pollution.
\end{abstract}

KEYWORDS: chironomid larvae, bio-indicator, mentum deformity, heavy metals, Mae Tao stream

\section{INTRODUCTION}

Cadmium contamination has been reported in rice, soils, and sediments in and around Mae Tao Stream, which is the main water resource for agricultural activities, located at Mae Sot District, Tak Province in the north of Thailand. Mae Tao Stream passes through a zinc mine area. The zinc mining has been actively operating for more than 30 years. Cadmium is naturally contained in zinc ore, and is a by-product of zinc mining. In about $69 \%$ of the sediment samples of Mae Tao Stream, cadmium concentrations exceeded the European maximum permissible level of $3.0 \mathrm{mg} / \mathrm{kg}$ for agricultural soil $^{1,2}$. Cadmium concentrations became higher in the sediments after the stream passed through the zinc mine, and then decreased along the distance from the zinc mine. Cadmium is a toxic metal which causes environmental problems. It concentrates in the human body through the food chain, and creates damages to the ecosystem ${ }^{3}$. The heavy contamination of cadmium in the sediments in Ban Pha De (zinc rich area) had been previously reported ${ }^{4}$.

The larvae of non-biting midges, one important group of invertebrates in the aquatic environment, have been widely used to assess environmental contamination. Non-biting midge larvae (Diptera: Chironomidae) have been proposed as good bioindicators of heavy metal pollution, because nonbiting midges are one of the dominant aquatic insect families in river ecosystem and their larvae are widely distributed and sensitive to many pollutants. Morphological abnormalities in non-biting midge larvae have been used as general indicators of anthropogenic stress in aquatic systems and in certain assessments of ecological risk ${ }^{5}$. Deformities are 
considered to be caused by the pollutants such as heavy metals, pesticides, and other compounds in water and sediment. Deformities related to environmental stress have been reported in other aquatic animals such as caddisflies and fish. However, most attention is directed to non-biting midge larvae because this insect group offers many advantages as bio-indicator for sediment pollution ${ }^{6}$. The nonbiting midge deformities often appear to present characteristic abnormalities of the mentum and ligulae in the head capsule, and their occurrence has been associated with environmental pollution by heavy metals ${ }^{7}$. However, there are few studies on morphological abnormalities of non-biting midge larvae, which are caused by cadmium. The objective of this study was to evaluate mouthpart deformities of non-biting midge larvae in Mae Tao Stream, polluted by cadmium.

\section{MATERIALS AND METHODS}

\section{Sampling sites}

Mae Tao Stream is located between latitude $16^{\circ} 39^{\prime}$ 9.0 $0^{\prime \prime}$ to $15^{\circ} 40^{\prime} 2.8^{\prime \prime} \mathrm{N}$ and longitude $98^{\circ} 36^{\prime} 6.6^{\prime \prime}$ to $98^{\circ} 42^{\prime} 2.6^{\prime \prime} \mathrm{E}$ in Mae Sot District, Tak Province, Northern Thailand, in the mountainous area of the border between Thailand and Myanmar. Mae Tao Stream is vital for life in Mae Sot District and is the main freshwater resource for drinking, irrigation, and agricultural purposes in many villages. There is a zinc mine along the upstream part of Mae Tao Stream in Phra That Padaeng Subdistrict. Since the operation of the zinc mining started in 1982, this area has been affected by the adverse impacts of heavy metals, especially cadmium which is contained in the effluents from the mine. The sampling sites are MT1 (Ban Tum Sua) and MT2 (before entering to the mine) are located upstream of the zinc mine and do not accept the water from the mine, and MT3 (Ban Phade) and MT4 (Ban Maetao Mai) are located downstream of the zinc mine and polluted by heavy metals.

\section{Physicochemical parameters}

Water samples were collected at 4 sampling sites every 2 months from April 2011 to February 2012. At each sampling site, physicochemical parameters such as water temperature, $\mathrm{pH}$, electrical conductivity (EC), and total dissolved solids (TDS) were measured in the field. Water samples were carried to the Freshwater Biomonitoring Research Laboratory, Faculty of Science, Chiang Mai University. Chemical parameters such as dissolved oxygen (DO), nitrate- nitrogen $\left(\mathrm{NO}_{3}{ }^{-}-\mathrm{N}\right)$, ammonia-nitrogen $\left(\mathrm{NH}_{3}-\mathrm{N}\right)$, and orthophosphate $\left(\mathrm{PO}_{4}{ }^{3-}\right)$ were analysed in the laboratory ${ }^{8}$.

\section{Analysis of cadmium concentrations in sediments}

At each sampling site, the upper layers of the sediments were collected from three points selected randomly for cadmium analysis. After mixing the sediments from 3 points, a portion of the sediment was kept in polyethylene bottle at $4^{\circ} \mathrm{C}$ until laboratory analysis ${ }^{9}$. The sediment samples $(5 \mathrm{~g})$ were dried at $80^{\circ} \mathrm{C}$ in hot air oven for $24 \mathrm{~h}$, and then digested with $1 \mathrm{ml}$ concentrated $\mathrm{HNO}_{3}$ and $3 \mathrm{ml}$ concentrated $\mathrm{HCl}$ in digestion vessels for $4 \mathrm{~h}$. Digested samples were allowed to cool, followed by addition of $25 \mathrm{ml}$ of $2 \% \mathrm{HNO}_{3}$. Finally, the solutions of $25 \mathrm{ml}$ were diluted with $10 \mathrm{ml}$ with deionized water and transferred to volumetric flasks prior to analyses. Cadmium concentration was analysed using inductively coupled plasma optical emission spectroscopy ${ }^{10}$.

\section{Evaluation of deformities of non-biting midge larvae}

To assess the deformities (morphological abnormalities) of non-biting midge larvae, the larvae of selected taxa were collected from polluted and unpolluted sites by kick and pick sampling techniques. In the laboratory, the head capsules were cleaned with $\mathrm{KOH}$, and then dehydrated with ethanol. The mouthpart deformities of non-biting midge were screened and identified under the standard light microscope at low powers $(10 \times$ to $40 \times)$. The different structures of deformities were photographed using the light microscopy ${ }^{11-13}$.

\section{Data analysis}

Biological and physicochemical parameters were analysed by statistic techniques, principally univariate analysis. Average and standard deviation of items at each study sites were calculated. The results of experiments were evaluated by statistical difference due to extended exposure periods between the 6 months using the SPSS 17.0 computer package. Results of testing were considered significant if calculated $p$-values were $<0.05$. The deformity incidences were calculated as the percentage (i.e., proportion) of deformed individuals to the total number of larvae screened within selected nonbiting midge taxa which were sampled from the same site ${ }^{14}$. 
Table 1 Means, standard deviations and ranges (in brackets) of physicochemical parameters in Mae Tao stream.

\begin{tabular}{|c|c|c|c|c|c|}
\hline Site & MT1 & MT2 & MT3 & MT4 & SWQS $^{\dagger}$ \\
\hline Location & Ban Tum Sua & Before mine & Ban Phade & Ban Maetao Mai & - \\
\hline Latitude & $16^{\circ} 39^{\prime} 9.94^{\prime \prime} \mathrm{N}$ & $16^{\circ} 39^{\prime} 9.04^{\prime \prime} \mathrm{N}$ & $16^{\circ} 40^{\prime} 2.82^{\prime \prime} \mathrm{N}$ & $16^{\circ} 40^{\prime} 1.26^{\prime \prime} \mathrm{N}$ & - \\
\hline Longitude & $98^{\circ} 42^{\prime} 2.65^{\prime \prime} \mathrm{E}$ & $98^{\circ} 40^{\prime} 2.63^{\prime \prime} \mathrm{E}$ & $98^{\circ} 37^{\prime} 7.10^{\prime \prime} \mathrm{E}$ & $98^{\circ} 36^{\prime} 6.67^{\prime \prime} \mathrm{E}$ & - \\
\hline Elevation (m) & 523 & 417 & 270 & 258 & - \\
\hline Temperature $\left({ }^{\circ} \mathrm{C}\right)$ & $\begin{array}{l}22.8 \pm 1.2^{\mathrm{a}} \\
(21.0-24.0)\end{array}$ & $\begin{array}{l}24.5 \pm 1.6^{a} \\
(23.0-26.0)\end{array}$ & $\begin{array}{l}24.4 \pm 1.7^{\mathrm{a}} \\
(23.0-26.0)\end{array}$ & $\begin{array}{c}23.9 \pm 2.6^{\mathrm{a}} \\
(21.0-26.0)\end{array}$ & $\mathrm{n}^{*}$ \\
\hline $\mathrm{pH}$ & $\begin{array}{l}8.12 \pm 0.17^{a} \\
(7.80-8.33)\end{array}$ & $\begin{array}{l}7.99 \pm 0.17^{a} \\
(7.70-8.27)\end{array}$ & $\begin{array}{l}8.16 \pm 0.22^{\mathrm{a}} \\
(7.80-8.51)\end{array}$ & $\begin{array}{l}8.11 \pm 0.21^{\mathrm{a}} \\
(7.80-8.41)\end{array}$ & $5.00-9.00$ \\
\hline $\mathrm{EC}(\mu \mathrm{S} / \mathrm{cm})$ & $\begin{array}{l}365 \pm 58^{\mathrm{a}} \\
(230-403)\end{array}$ & $\begin{array}{l}390 \pm 91^{\mathrm{a}} \\
(192-466)\end{array}$ & $\begin{array}{l}389 \pm 74^{a} \\
(216-467)\end{array}$ & $\begin{array}{l}402 \pm 80^{\mathrm{a}} \\
(198-475)\end{array}$ & - \\
\hline TDS (mg/l) & $\begin{array}{l}191 \pm 29^{a} \\
(119-214)\end{array}$ & $\begin{array}{l}213 \pm 50^{\mathrm{a}} \\
(104-258)\end{array}$ & $\begin{array}{l}193 \pm 48^{\mathrm{a}} \\
(112-248)\end{array}$ & $\begin{array}{l}212 \pm 41^{\mathrm{a}} \\
(114-254)\end{array}$ & - \\
\hline DO (mg/l) & $\begin{array}{l}7.72 \pm 0.59^{\mathrm{a}} \\
(6.80-8.80)\end{array}$ & $\begin{array}{l}7.47 \pm 0.47^{\mathrm{ab}} \\
(7.00-8.40)\end{array}$ & $\begin{array}{l}7.12 \pm 0.46^{b} \\
(6.20-7.60)\end{array}$ & $\begin{array}{l}7.28 \pm 0.30^{b} \\
(6.80-7.80)\end{array}$ & 4.00 \\
\hline $\mathrm{NO}_{3}{ }^{-}-\mathrm{N}(\mathrm{mg} / \mathrm{l})$ & $\begin{array}{l}1.12 \pm 0.51^{\mathrm{a}} \\
(0.40-2.00)\end{array}$ & $\begin{array}{l}1.58 \pm 0.65^{\mathrm{ab}} \\
(0.40-2.80)\end{array}$ & $\begin{array}{l}1.95 \pm 0.89^{b} \\
(0.70-3.40)\end{array}$ & $\begin{array}{l}1.92 \pm 0.91^{\mathrm{b}} \\
(0.20-3.40)\end{array}$ & 5.00 \\
\hline $\mathrm{NH}_{3}-\mathrm{N}(\mathrm{mg} / \mathrm{l})$ & $\begin{array}{l}0.13 \pm 0.11^{\mathrm{a}} \\
(0.01-0.37)\end{array}$ & $\begin{array}{l}0.17 \pm 0.06^{\mathrm{a}} \\
(0.10-0.36)\end{array}$ & $\begin{array}{l}0.19 \pm 0.10^{\mathrm{a}} \\
(0.05-0.40)\end{array}$ & $\begin{array}{l}0.22 \pm 0.15^{\mathrm{a}} \\
(0.01-0.53)\end{array}$ & 0.50 \\
\hline $\mathrm{PO}_{4}^{3-}(\mathrm{mg} / \mathrm{l})$ & $\begin{array}{l}0.31 \pm 0.20^{\mathrm{a}} \\
(0.11-0.78)\end{array}$ & $\begin{array}{l}0.34 \pm 0.25^{a} \\
(0.12-0.89)\end{array}$ & $\begin{array}{l}0.24 \pm 0.10^{\mathrm{a}} \\
(0.09-0.44)\end{array}$ & $\begin{array}{l}0.43 \pm 0.34^{\mathrm{a}} \\
(0.12-1.47)\end{array}$ & - \\
\hline $\mathrm{Cd}(\mathrm{mg} / \mathrm{kg})$ & $\begin{array}{l}0.84 \pm 0.22 \\
(0.58-0.98)\end{array}$ & $\begin{array}{l}2.47 \pm 0.34 \\
(2.13-2.82)\end{array}$ & $\begin{array}{c}5.3 \pm 1.8 \\
(4.07-7.43)\end{array}$ & $\begin{array}{c}7.9 \pm 4.0 \\
(4.32-12.14)\end{array}$ & - \\
\hline
\end{tabular}

$\dagger$ SWQS = Surface Water Quality Standards of Thailand (changing not more than $3{ }^{\circ} \mathrm{C}$ ). ${ }^{\star} \mathrm{n}=$ naturally. Different superscript letters per variable across sites indicate significant differences established using the Tukey HSD test while the same superscript letter indicates no significant difference.

\section{RESULTS AND DISCUSSION}

\section{Physicochemical parameters}

Means, standard deviations and ranges of physicochemical parameters measured at the four sampling sites are shown in Table 1 . The $\mathrm{pH}$ measurement is one of the most important and frequently used tests in water chemistry. $\mathrm{pH}$ affects the solubility and availability of nutrients which can be utilized by aquatic organisms. Natural freshwater usually has $\mathrm{pH}$ values between 6 and 8. According to the present results, $\mathrm{pH}$ was found to range from 7.70 (MT2) to 8.51 (MT3). Statistical results showed no significant difference $(p<0.05)$ among the sites, and the $\mathrm{pH}$ values are within the permissible limit (5.00-9.00) of Surface Water Quality Standards of Thailand (1995). Electrical conductivity (EC) is the ability of the water to conduct an electrical current, and is an indirect measure of the ion concentration. The major ions contributing to the conductivity are sodium, potassium, calcium, magnesium, chloride, and sulphate. Other ions that contribute to conductivity to a smaller degree are carbonate, bicarbonate, nitrate, and phosphate ${ }^{15}$. In this study, EC values ranged from 365-402 $\mu \mathrm{S} / \mathrm{cm}$ (Table 1) and were high at all sampling sites. The results tested statistically showed no significant difference among sampling sites. TDS were measured in the range of $193-212 \mathrm{mg} / 1$. TDS values were not significant different among the sampling sites. The high value of TDS is usually caused by leaching of ions to the stream from soil. The concentration and composition of TDS in natural waters is determined by the geology of the drainage, atmospheric precipitation and the water balance (evaporation- precipitation) ${ }^{16}$. For freshwater animals, TDS toxicity is a result of osmotic stress and its impacts on the osmoregulatory capability of the organism ${ }^{17}$.

The concentrations of dissolved oxygen (DO) were $7.24-7.67 \mathrm{mg} / \mathrm{l}$, and showed no significant difference among sampling sites. DO was more than $4 \mathrm{mg} / \mathrm{l}$, the limit value of the Surface Water Quality Standard at all sampling sites both upstream and downstream of the mine. Nitrate-nitrogen $\left(\mathrm{NO}_{3}{ }^{-}-\right.$ $\mathrm{N})$ and ammonia-nitrogen $\left(\mathrm{NH}_{3}-\mathrm{N}\right)$ are the most common forms of nitrogen in aquatic systems, that 
is often the limiting factor for biological productivity of the water. The highest value of $\mathrm{NO}_{3}{ }^{-}-\mathrm{N}$ was detected at MT3. This site is near the agriculture area and the soil with fertilizer seems to be eroded into the water. As result, the concentration of $\mathrm{NO}_{3}{ }^{-}-\mathrm{N}$ increased in the stream. The lowest value of $\mathrm{NO}_{3}{ }^{-}-\mathrm{N}$ was detected at MT1. Based on statistical analysis, there were significant difference $(p<0.05)$ among the sampling sites. $\mathrm{NH}_{3}-\mathrm{N}$ is excreted by animals and produced by decomposition of plants and animals, and may return to increased concentration of $\mathrm{NO}_{3}{ }^{-}-\mathrm{N}$ in the stream. The lowest value of $\mathrm{NH}_{3}-\mathrm{N}$ was detected at MT1. Based on statistical analysis, there were no significant difference $(p<0.05)$ among the sites. The concentration of $\mathrm{NH}_{3}-\mathrm{N}$ did not exceed the water quality standard of Thailand $(0.5 \mathrm{mg} / \mathrm{l})$ at almost all the sampling sites. Orthophosphate $\left(\mathrm{PO}_{4}{ }^{3-}\right)$ is generally considered to be the primary nutrient limiting algal and plant growth in fresh waters. In this study, the ranges of $\mathrm{PO}_{4}{ }^{3-}$ concentration were $0.24-0.43 \mathrm{mg} / \mathrm{l}$ (Table 1). $\mathrm{PO}_{4}{ }^{3-}$ concentration levels were not significant different among the sites. The values of alkalinity and the total hardness of Mae Tao Stream were the same for the four sampling sites. According to the physicochemical parameters, the water quality did not exceed the values of the Surface Water Quality Standard of Thailand and seems to be not affected by the zinc mine.

\section{Cadmium concentrations in the sediments}

Cadmium (Cd) concentrations in the sediments of Mae Tao Stream were analysed. The Cd concentration in all sampling sites ranged from 0.84$7.86 \mathrm{mg} / \mathrm{kg}$. As shown in Fig. 1, the highest concentration of cadmium was detected at MT4, while the lowest concentration was detected at MT1. Cd concentration at MT3 and MT4 were much higher than those at MT1 and MT2. Cd concentrations of MT3 and MT4 exceeded the European Maximum Permissible Levels for Agricultural Soil ( $>3.0 \mathrm{mg} / \mathrm{kg}$ ). MT1 and MT2 are located upstream the zinc mine, and MT1 is very far from the zinc mine. MT3 and MT4 are located downstream the zinc mine. As Mae Tao Stream accepts the water from the zinc mine, it is clear that the source of $\mathrm{Cd}$ is the zinc mine. Cd contamination in sediment affects aquatic organisms through bio-accumulation, resulting in potential long term implication on human health and ecosystem. Cadmium is an extremely toxic metal to animals and human. In human, cadmium exerts toxic effects on the kidney, the skeletal system and the respiratory system and is classified as a

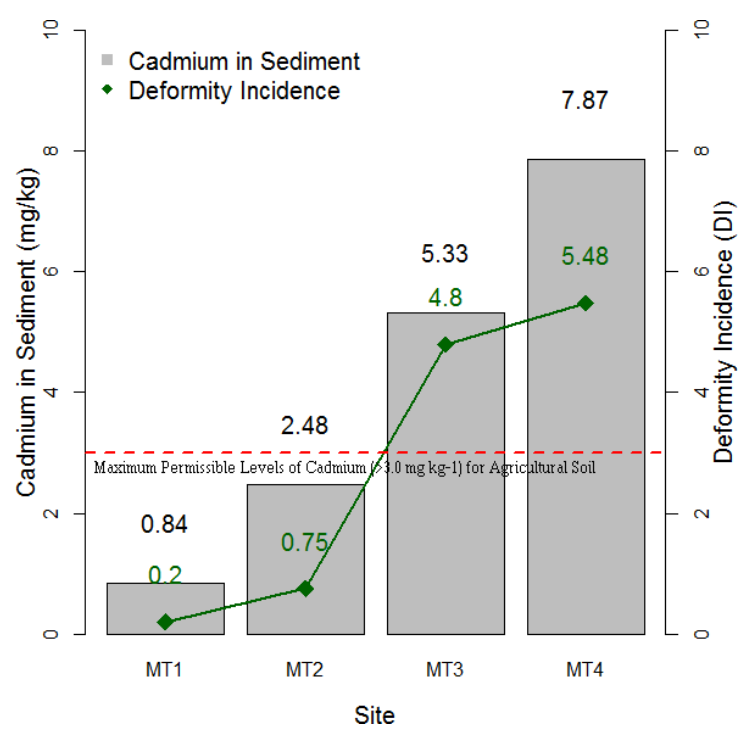

Fig. 1 Concentrations of cadmium in sediments of Mae Tao stream in a horizontal line and the right axis: the trend of chironomid deformity incidences in the sites.

human carcinogen ${ }^{18}$.

\section{Mouthpart deformities in non-biting midge larvae}

Many studies reported the deformities in the head capsules (mentum in particular) of non-biting midge larvae. Several other authors reported that morphological deformities of various non-biting midge taxa occur when they are exposed to contaminants ${ }^{19,20}$. Non-biting midges are a highly diverse group of insects. Members of this family are often included in programs monitoring the health of freshwater ecosystems.

A total of 3067 non-biting midge larvae and 21 taxa were identified from this study (Tribe Chironomini Chironomus sp., Cladopelma sp., Cladotanytarsus sp., Cryptochironomus sp., Cryptotendipes sp., Demicryptochironomus sp., Dicrotendipes sp., Kiefferulus sp., Microtendipes sp., Neozavrelia sp., Paratanytarsus sp., Polypedilum sp., Pseudochironomus sp., Saetheria sp., Shangomyia sp., Stictochironomus sp., Sublette sp., and Zavrelia sp.; Tribe Tanytarsini Micropsectra sp. and Tanytarsus sp.; Orthocladiinae, and Tanypodinae) representing 3 subfamilies (Chironominae, Orthocladiinae and Tanypodinae). Furthermore, non-biting midge larvae were screened for analysis of mouthpart deformities (Table 2). The most deformity of non-biting midges mouthpart was found in site MT4 which comprises $5.5 \%$ of the total 639 larvae collected. In site MT3, 
Table 2 A number of individuals of mentum deformities among non-biting midge taxa sampled at the 4 sites of Mae Tao stream.

\begin{tabular}{|c|c|c|c|c|}
\hline Таха & MT1 & MT2 & MT3 & MT4 \\
\hline \multicolumn{5}{|l|}{ Chironominae } \\
\hline Chironomus sp. & $2 / 458$ & $0 / 4$ & $8 / 21$ & $14 / 176$ \\
\hline Cladopelma sp. & $0 / 39$ & $0 / 243$ & $6 / 15$ & $2 / 5$ \\
\hline Cladotanytarsus sp. & $0 / 0$ & $0 / 1$ & $0 / 1$ & $0 / 0$ \\
\hline Cryptochironomus sp. & $0 / 3$ & $0 / 53$ & $0 / 10$ & $0 / 25$ \\
\hline Cryptotendipes sp. & $0 / 0$ & $0 / 3$ & $0 / 35$ & $0 / 2$ \\
\hline $\begin{array}{l}\text { Demicryptochiro- } \\
\text { nomus sp. }\end{array}$ & $0 / 0$ & $0 / 2$ & $0 / 4$ & $0 / 0$ \\
\hline Dicrotendipes sp. & $0 / 95$ & $0 / 0$ & $0 / 0$ & $0 / 0$ \\
\hline Kiefferulus sp. & $0 / 0$ & $0 / 1$ & $0 / 55$ & $0 / 8$ \\
\hline Microtendipes sp. & $0 / 7$ & $0 / 12$ & $0 / 1$ & $0 / 3$ \\
\hline Neozavrelia sp. & $0 / 0$ & $0 / 0$ & $0 / 1$ & $0 / 1$ \\
\hline Paratanytarsus sp. & $0 / 24$ & $0 / 17$ & $0 / 3$ & $0 / 0$ \\
\hline Polypedilum sp. & $0 / 308$ & $7 / 370$ & $5 / 297$ & $12 / 250$ \\
\hline Pseudochironomus sp. & $0 / 1$ & $0 / 0$ & $0 / 0$ & $0 / 0$ \\
\hline Saetheria sp. & $0 / 0$ & $0 / 2$ & $0 / 2$ & $0 / 0$ \\
\hline Shangomyia sp. & $0 / 0$ & $0 / 1$ & $0 / 0$ & $0 / 0$ \\
\hline Stictochironomus sp. & $0 / 13$ & $0 / 1$ & $1 / 3$ & $0 / 0$ \\
\hline Sublette sp. & $0 / 0$ & $0 / 2$ & $0 / 1$ & $0 / 0$ \\
\hline Zavrelia sp. & $0 / 4$ & $0 / 0$ & $0 / 0$ & $0 / 0$ \\
\hline Tribe Tanytarsini & & & & \\
\hline Micropsectra sp. & $0 / 1$ & $0 / 88$ & $0 / 6$ & $0 / 164$ \\
\hline Tanytarsus sp. & $0 / 0$ & $0 / 19$ & $4 / 9$ & $0 / 2$ \\
\hline Orthocladiinae & $0 / 19$ & $0 / 22$ & $0 / 0$ & $7 / 38$ \\
\hline Tanypodinae & $0 / 30$ & $0 / 85$ & $0 / 36$ & $0 / 65$ \\
\hline Total & $2 / 1002$ & $7 / 926$ & $24 / 500$ & $35 / 639$ \\
\hline
\end{tabular}

the overall observed deformity incidence was $4.8 \%$ of the total 500 larvae collected. At site MT2, a deformity incidence around $0.75 \%$ of the total 926 larvae collected was observed. According to site MT1, only 2 larvae were successfully mounted for the deformity represented by $0.20 \%$ (Table 3 ). The non-biting midge of the subfamily Chironominae were more deformed comparing to members of other subfamilies (Tanypodinae and Orthocladiinae) (Table 2).

The increasing of mouthpart deformities from

Table 3 Mouthpart deformities incidence in 4 sampling sites of Mae Tao stream.

\begin{tabular}{lcccc}
\hline Sampling sites & MT1 & MT2 & MT3 & MT4 \\
\hline No. of individuals & 1002 & 926 & 500 & 639 \\
No. of deformed individuals & 2 & 7 & 24 & 35 \\
Deformity incidence & 0.20 & 0.75 & 4.80 & 5.48 \\
\hline
\end{tabular}
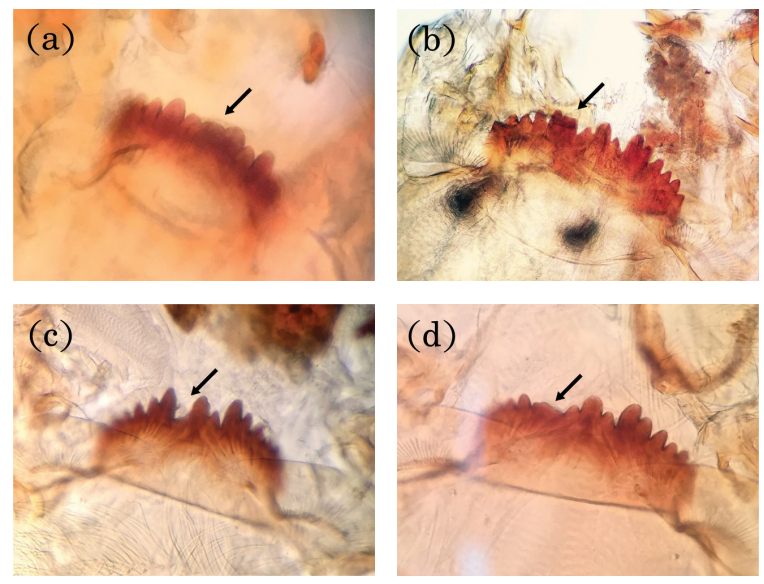

Fig. 2 Typical patterns of mouthpart deformities of nonbiting midge larvae; (a) missing median of Polypedilum sp. in MT3, (b) fuse right lateral in Chironomus sp. in MT4, (c) Kohn gap in Chironomus sp. in MT4 and (d) missing right lateral teeth of Chironomus sp. in MT4.

upstream to downstream indicated the pollution stress in the Mae Tao Stream. The typical patterns of mouthpart deformities of non-biting midge larvae in this study are shown in Fig. 2. The highest deformity incidence of non-biting midges mouthpart, $5.5 \%$ of the total 639 larvae, was obtained in MT4 (Table 3). The deformities in non-biting midge larval mentum amounted to $0.20,0.75,4.8$, and $5.5 \%$ in the MT1, MT2, MT3, and MT4, respectively. The total deformity incidence was strongly correlated with high contents of sediment cadmium (Fig. 1). Mouthpart deformities in non-biting midge larvae were used as a biomonitoring tool for heavy metal pollution in the Uganda section of northern Lake Victoria. The result found that non-biting midge had no deformity at the reference sites, while in urban-industrial sites the deformities ranged from $3.7 \%$ to $4.7 \%$ of non-biting midges showed deformities. Non-biting midge mouthpart deformities correlated with concentrations of copper and zinc among the listed metals, but not correlated with the physical variables. Natural incidence of deformities in non-biting midges was reported to be less than $1 \%$, based on subfossil records, and thus the incidence was more than $1 \%$ at polluted sites $^{21}$. Furthermore, the researchers studied the relationship between heavy metal contamination and mouthpart deformities in non-biting midges and used non-biting midge mouthpart deformities as a practical means of assessing the biological impact caused by heavy metal contamination in aquatic 
systems from mining activities. Their result indicates that non-biting midge larvae collected from contaminated sites exhibit proportions of mouthpart deformity between 3.8 and $10 \%$ compared to the reference site of $0.9 \%^{22}$. Odume et al studied deformities in the mouthparts of larval non-biting midge, particularly of the mentum, representing sublethal effects by exposure to pollutants, and then used as indicators of pollution in the Swartkops River ${ }^{14}$. Non-biting midge larvae were collected using the South African Scoring System 5 (SASS) protocol $^{23}$. A total of 4838 larvae, representing 26 taxa from 4 sampling sites during four seasons, were screened for mentum deformities. The community incidences of mentum deformity were consistently higher than $8 \%$ at the sites indicating pollution stress in the river. Furthermore, researchers have studied the occurrence of head capsule deformities in first instar larvae of Chironomus riparius Meigen, 1804 (Diptera Chironomidae). The results gave rise to four hypotheses: (a) teratogenic effects of contaminants in the water, (b) teratogenic effects of contaminants accumulated in the mother's body, (c) genetic inheritance of contamination-induced mutations, and (d) spontaneous dysgenesis. All the hypotheses considered are not mutually exclusive, but a combination of two or more causes could increase the deformity frequencies in the first instar larvae ${ }^{24}$. In this study, the results confirmed that deformity incidences were much higher in the sediments polluted by cadmium (MT3 and MT4) than in the unpolluted sites (MT1 and MT2) as shown in Fig. 1.

\section{CONCLUSIONS}

In Mae Tao Stream, Mae Sot District, Tak Province, Thailand, which passes through the zinc mine, the water quality, concentrations of cadmium and mouthpart deformities were analysed. Physicochemical parameters such as water temperature, $\mathrm{pH}$, electrical conductivity, total dissolved solids, dissolved oxygen, nitrate-nitrogen, ammonia-nitrogen, and orthophosphate did not exceed the values of the standard of Thailand at all study sites in Mae Tao Stream, and showed not much difference among all the study sites. However, cadmium concentrations in the sediments showed big difference between the polluted sites by cadmium downstream of the zinc mine and unpolluted sites upstream of the mine. The highest concentration of cadmium was $7.86 \mathrm{mg} / \mathrm{kg}$, while the lowest concentration was $0.84 \mathrm{mg} / \mathrm{kg}$. Mouthpart deformity incidence of non-biting midge larvae was around 5\% in polluted sites by cadmium, much higher than the unpolluted sites where deformity incidences were less than $1 \%$. This study confirmed that the mouthpart deformity incidence of non-biting midge larvae was positively correlated with the concentration of cadmium in the sediment.

Acknowledgements: The authors would like to thank Centre of Excellence on Environmental Health Toxicology and Centre of Excellence on Entomology and Application for financial support. We also thank Freshwater Biomonitoring Research Laboratory, Environmental Chemistry Research Laboratory and Environmental Science Programme, Faculty of Science, Chiang Mai University for facility on field study and water quality analyses. Chiang Mai University and Graduate School of Chiang Mai University are also gratefully acknowledged.

\section{REFERENCES}

1. Simmons RW, Pongsakul P, Saiyasitpanich D, Klinphoklap S (2005) Elevated levels of cadmium and zinc in paddy soils and elevated levels of cadmium in rice grain downstream of a zinc mineralized area in Thailand: implications for public health. Environ Geochem Health 27, 501-11.

2. Sriprachote A, Kanyawongha P, Ochiai K, Matoh T (2012) Current situation of cadmium-polluted paddy soil, rice and soybean in the Mae Sot District, Tak Province, Thailand. Soil Sci Plant Nutr 58, 1-11.

3. Satarug S, Baker JR, Urbenjapol S, Haswell-Elkins MP, Reilly E, Williams DJ, Moore MR (2003) A global perspective on cadmium pollution and toxicity in non-occupationally exposed population. Toxicol Lett 137, 65-83.

4. Thanee I, Phalaraksh C (2012) Diversity of aquatic insects and their functional feeding group from anthropogenically disturbed streams in Mae Sot District, Tak Province, Thailand. Chiang Mai J Sci 39, 399-409.

5. Bird GA (1994) Use of chironomid deformities to assess environmental degradation in the Yamaska River. Environ Monit Assess 30, 163-75.

6. Warwick WF, Tisdale NA (1988) Morphological deformities in Chironomus, Cryptochironomus and Procladius (Diptera: Chironomidae) from two differentially stressed sites in Tobin lakes, Saskatchewan. Can $J$ Fish Aquat Sci 45, 1123-44.

7. Janssens de Bisthoven L, Van Speybroeck D (1994) Some observations of deformed midge larvae (Diptera, Chironomidae) in Kenya. Verh Internat Verein Limnol 25, 2485-9.

8. American Public Health Association (1992) Standard Methods for the Examination of Water and Wastewater, APHA, AWWA, WPCF, Washington DC, USA.

9. Wencuan Q, Dickman M, Sumin W (2001) Multivariate analysis of heavy metal and nutrient concentra- 
tions in sediments of Taihu Lake, China. Hydrobiologia 450, 83-9.

10. Merian E (1991) Metals and Their Compounds in the Environment: Occurrence, Analysis and Biological Relevance, VCH, Weinheim, Germany.

11. Janssens de Bisthoven L, Vermeulen A, Ollevier F (1998) Experimental induction of morphological deformities in Chironomus riparius larvae by chronic exposure to copper and lead. Arch Environ Contam Toxicol 35, 249-56.

12. Lenat DR (1993) Mentum deformities of Chironomus larvae to evaluate the effects of toxicity and organic loading in streams. J N Am Benthol Soc 12, 265-9.

13. MacDonald EE, Taylor BR (2006) Incidence of mentum deformities in midge larvae (Diptera:Chironomidae) from Northern Nova Scotia, Canada. Hydrobiologia 563, 277-87.

14. Odume ON, Muller WJ, Palmer CG, Arimoro FO (2012) Mentum deformities in Chironomidae communities as indicators of anthropogenic impacts in Swartkops River. Phys Chem Earth 50, 140-8.

15. Fernandez G, Chescheir GM, Skaggs RW, Amatya DM (2002) WATGIS: A GIS-based lumped parameter water quality model. Trans ASAE 45, 593-600.

16. Weber-Scannell PK, Duffy LK (2007) Effects of total dissolved solids on aquatic organisms: A review of literature and recommendation for salmonid species. Am J Environ Sci 3, 1-6.

17. McCulloch WL, Goodfellow WL, Black JA (1993) Characterization, identification and confirmation of total dissolved solids as effluent toxicants. Environ Monit Assess 2, 213-27.

18. World Health Organization (2007) Health Risks of Heavy Metals from Long-Range Transboundary Air Pollution, WHO, Denmark.

19. Hamilton AL, Sæther OA (1971) The occurrence of characteristic deformities in the chironomid larvae of several Canadian lakes. Can Entomol 103, 363-8.

20. Wiederholm $\mathrm{T}$ (1984) Incidence of deformed chironomid larvae (Diptera: Chironomidae) in Swedish lakes. Hydrobiologia 109, 243-9.

21. Swansburg EO, Fairchild WL, Fryer BJ, Ciborowswi $\mathrm{JH}$ (2002) Mouthpart deformities and community composition of Chironomid (Diptera) larvae downstream of metal mines in New Brunswick, Canada. Environ Toxicol Chem 21, 2675-84.

22. Martinez EA, Moore BC, Schaumloffel J, Dasgupta $\mathrm{N}$ (2002) The potential association between menta deformities and trace elements in Chironomidae (Diptera) taken from a heavy metal contaminated river. Arch Environ Contam Toxicol 42, 286-91.

23. Dickens CWS, Graham PM (2002) The South African Scoring System (SASS) version 5 rapid bioassessment method for rivers. Afr J Aquat Sci 27, 1-10.

24. Servia MJ, Cobo F, González MA (2000) Incidence and causes of deformities in recently hatched larvae of Chironomus riparius MEIgen, 1804 (Diptera, Chi- ronomidae). Arch Hydrobiol 149, 387-401. 